University of Massachusetts Amherst

ScholarWorks@UMass Amherst

Masters Theses 1911 - February 2014

1972

\title{
Processing capacity in a letter-matching task.
}

Elizabeth Mclean Comstock

University of Massachusetts Amherst

Follow this and additional works at: https://scholarworks.umass.edu/theses

Comstock, Elizabeth Mclean, "Processing capacity in a letter-matching task." (1972). Masters Theses 1911 - February 2014. 1410.

https://doi.org/10.7275/w71p-rr74

This thesis is brought to you for free and open access by ScholarWorks@UMass Amherst. It has been accepted for inclusion in Masters Theses 1911 - February 2014 by an authorized administrator of ScholarWorks@UMass Amherst. For more information, please contact scholarworks@library.umass.edu. 
UMASS/AMHERST

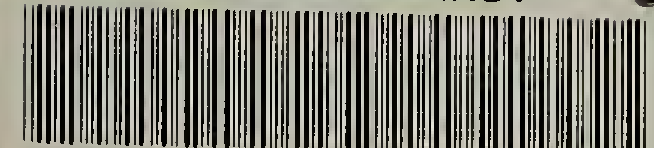

3120660135646 I ? 
PROCESSING CAPACITY IN A LETTER-MATCHING TASK

A Thesis Presented

by

Elizabeth M. Comstock

Submitted to the Graduate school of the University of Massachusetts in partial fulfillment of the requirements for the degree of

MASTER OF SCIENCE

March, 1972

PSYCHOLOGY 
ii

PROCESSING CAPACITY IN A LETTER-MATCHING TASK

A Thesis by

Elizabeth M. Comstock

Approved as to style and content by:
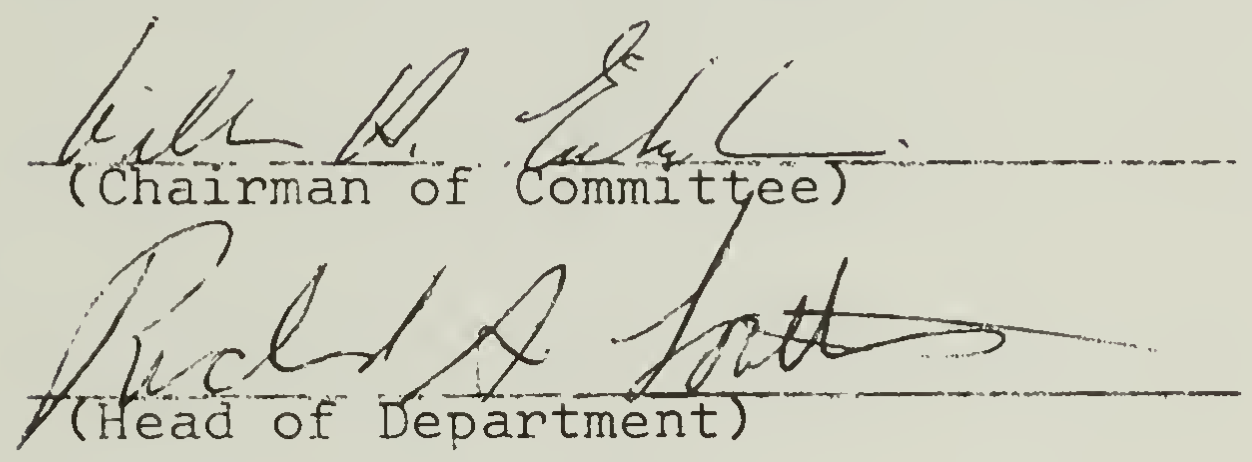

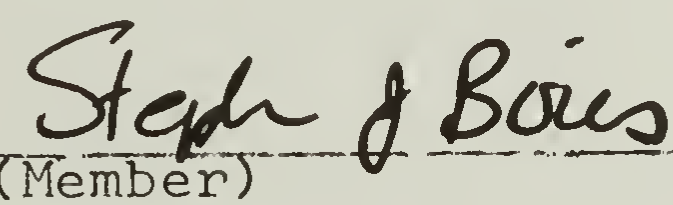
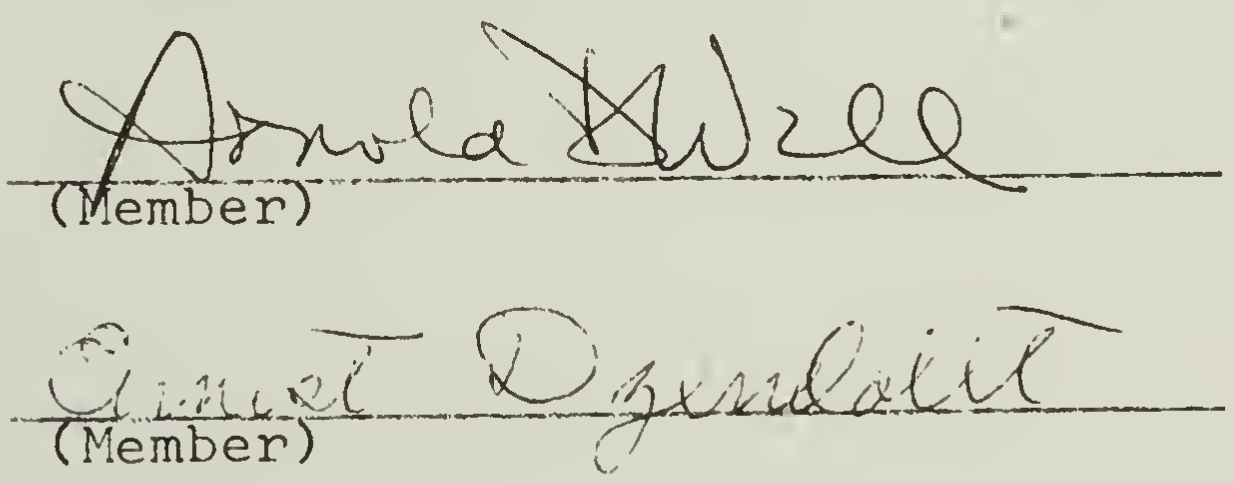

$-\frac{7 / \text { cent }}{\text { (Month) }}, \frac{972}{(\text { Year })}$ 


\section{iii}

Acknowledgments

Among the many people whom I would like to thank for their guidance and help with this thesis are my advisor, Bill Eichelman, and the other members of my thesis committee, Stephen Boies, Arnold Well, and Ernest Dzendolet.

The data for this experiment were all collected while the author was employed by IBM as a Research Assistant at the Thomas $\mathrm{J}$. Watson Research Center in Yorktown Heights, ivew York. There are a great many people there I should like to thank. Immeasurable help and kindness were shown to me by Stephen Boies, John Gould, Peter Welch, and the other members of the Psychology Research Group. The people with whom I shared the use of the 1800 computer were very generous in assisting with equipment problems and in scheduling experimental sessions. Also, the TSS computer staff and consultants were very helpful with the initial analysis of data. During the planning stages and the final analysis and writing, the author was supported by an NDEA Fellowship. Partial support was also obtained from NSF Departmental Development Grant GU 40-4I. Funds for data analysis were provided by a grant from the University of Massachusetts Computing Center. 
Table of Contents

Acknowledgments . . . . . . . . . . . . iii

List of Illustrations . . . . . . . . . . v

Abstract. . . . . . . . . . . . . . . . 1

Introduction. . . . . . . . . . . . . 2

Method. . . . . . . . . . . . . . . 15

Subjects . . . . . . . . . . . . 15

Apparatus and Stimuli. . . . . . . . . 15

Primary and Probe Tasks. . . . . . . . 18

Design and Procedure . . . . . . . . 24

Results . . . . . . . . . . . 27

Error Trials . . . . . . . . . 28

Probe RTS. . . . . . . . . . . . 32

RTs on the Letter-Matching Task. . . . . 37

Discussion. . . . . . . . . . . . 41

References. . . . . . . . . . . . 53

Appendix A. . . . . . . . . . . . 57

Appendix B. . . . . . . . . . . . . 59 
List of Illustrations

Table 1. Time in milliseconds of primary and probe task events. . . . . . . . . . 19

Figure 1. Number of errors on the lettermatching and probe tasks under No Mask Conditions as a function of probe position . . . . . . . . . 30

Figure 2. Probe RTs as a function of the position of the probe relative to the events in the letter-matching task . . . . 33

Figure 3. RT's on the letter-matching task under No Mask Conditions as a function of probe position . . . . . . 38 


\section{Abstract}

A processing-capacity notion of attention was defined in terms of increased reaction times ( $R T S$ ) in a probe task at specific times during the performance of a primary task. The primary task involved a same-different response to two letters presented successively. The probe task was either a Donders type a or type $\subseteq$ reaction to a burst of white noise, which could occur at any one of 8 times relative to the events on the letter-matching task. The study was specifically designed to investigate the encoding of the first letter, which Posner and Boies (1971) concluded required no processing capacity. Here, displaying the first letter for $15 \mathrm{msec}$. and following it with a visual mask did result in lengthened RTs to probes presented simultaneously with the first letter. Increasing the difficulty of the probe task did not result in greater interference from the primary task. Data are discussed in terms of processes requiring capacity. 


\section{Introduction}

The study of attention by psychologists has a history dating from the beginnings of experimental psychology in the latter part of the 19 th century. Throughout that history, attention has been used as an explanatory concept with many disparate definitions. Boring (in Mostofsky, 1970) identified ten uses of attention in the period between 1850 and 1930. Definitions of attention ranged from "an expectant attitude" to "an attribute of the clearness of a sensation," and the methodologies employed were as different as measurement of reaction time and analytical introspection. Woodworth and Schlosberg (1954, p. 72) described a similar list of uses and concluded that "in spite of the practical reality of attending, the status of attention in systematic psychology has been uncertain and dubious for a long time."

The current state of the concept of attention seems to be little improved. Moray (1970) presented seven uses of the term in recent research. His list included mental concentration, vigilance, selective attention, search, activation, set, and analysis by synthesis. 'I'he tasks which have been used to investigate each of these kinds 
of attention are strikingly different and comparisons between them are difficult to draw. It is not always clear in what ways the phenomena sharing the use of the word "attention" are related.

One way to help clarify the study of attention is to try to carefully define and identify various processes or components of attention within a single experimental paradigm. Posner and Boies (1971) have recently made use of a letter-matching task to study three components of attention. Very briefly, their paradigm was as follows: on each trial two letters were presented on a visual display and $S$ presses one of two keys for "same" letters or "different" letters as rapidly as possible. The dependent measure was reaction time (RT). Ss were instructed to respond "same" to physically identical letters, letters with the same name, or letters which were both vowels or Doth consonants. Although level of instruction had systematic effects on RT (see also Posner and Mitchell, 1967 ; Posner, Boies, Eichelman, \& Taylor, 1969), the attentional processes to be described here had very similar effects at all levels of instruction. Other variables manipulated in different experiments were the presence or absence of a warning signal prior to the onset of the first letter, the length of the interval between the warning signal and the 
first letter (warning interval--WI), the length of the interval between the onsets of the two letters (interstimulus interval--ISI), and the duration of the first letter. Also, on half the trials in some experiments, Ss were required to perform a secondary task in addition to the primary letter-matching task. The secondary, or probe, task consisted of simple key press responses to the onset of white noise. Probes could occur at any one of eight times relative to the sequence of events in the lettermatching task.

Three component processes associated with attention in the letter-matching task were operationally defined by Posner and Boies. Nonspecific preparation was defined as the processes occurring after presentation of a warning signal which resulted in faster performance on the lettermatching task. The preparation function, or the change in RT with changes in WIs, has been found to reach a minimum at WIs between 200 and $500 \mathrm{msec}$. (Posner and Wilkinson, 1969). Similar optimal WI lengths have been reported for a number of other tasks in which the warning signal provided reliable information about when the signal related to the response would occur (see Bertelson, 1967). Preparation was viewed by Posner and Boies as related to vigilance and general sensitivity to external stimulation. 
In the letter-matching plus probe task, the nonspecific nature of preparation was indicated by the fact that RTs to the noise probes were faster when the probe occurred within about $700 \mathrm{msec}$. following the warning signal, even though the warning signal gave information about the arrival of the letter stimuli and did not reliably cue probe presentations.

The second attentional component was related to S's ability to use specific information about the first letter in dealing with the second letter. Given a WI of $500 \mathrm{msec}$, the process of selective attention was reflected in the decreasing RIs to respond "same" or "different" as the ISI increased from 0 to about $500 \mathrm{msec}$. When the onset of the second letter was delayed by $1000 \mathrm{msec}$, RTs tended to rise slightly. This relationship between RT and ISI, called the encoding function, was similar to the preparation function in that the optimal interval was about 500 msec. However, preparation and encoding were found by Posner and Boies to be separable processes which could occur either individually or at the same time without interference. When no warning signal preceded the first letter and the ISI increased from 0 to 150 to $500 \mathrm{msec}$, the first letter was assumed to initiate both preparation and encoding. In this situation the improvement in RT with 
lengthening ISI was equal to the summed decreases from the preparation and encoding functions alone. These results were taken as evidence that preparation in the form of a warning signal and the selective encoding possible after presentation of the first letter were distinct attentional processes.

The operation of a limited capacity mechanism is the third sense of attention investigated by Posner and Boies, and the main focus of the research being reported here. It is an old and commonplace observation that a person is limited in the activities and mental operations he can perform at one time. William James (1890, p. 404) recognized that attention "implies withdrawal from some things in order to deal effectively with others." One way to study this restricted ability to pay attention is to postulate that somewhere in the sequence of events between the occurrence of a stimulus and the execution of a response there exists a mechanism with finite ability to handle simultaneous tasks. When too much is demanded of the system at once, the excess operations might be ignored completely, handled only partially or more slowly, or delayed until such time as the limited capacity system has room for them. In this sense, paying attention refers to the allocation of processing capacity. 
In order to study the processing capacity requirements of various mental operations in the letter-matching task, Posner and Boies assumed that any two operations requiring access to the limited capacity system would tend to interfere with each other. If this were true, then the amount of interference would reflect the degree to which the two tasks made incompatible demands for processing capacity. It is not a new notion that interference between dual tasks can provide information about their central processing requirements. Woodworth and Schlosberg (1954) cited several early studies (Paulhan, 1887; Binet, 1890; and Jastrow and Cairnes, 1891-1892) in which one or both of two simultaneous performances showed impairment over performance on that task alone. More recently, Bahrick, Noble, and Fitts (1954) used an arithmetic task to measure the capacity demands of various motor tasks. Baddeley (1966) found that the generation of random letter sequences reflected the difficulty of a card-sorting task. Posner and Keele (1967), and Ells (1970) studied the attention required during a movement task by measuring the interference in a RT task depending, on when the signal to react occurred during the movement task. Also closely related are studies of the psychological refractory period, which indicate that the $\mathrm{RT}$ to the second of two signals presented in quick succession is prolonged, 
probably due to operations of response selection for the first signal (see Smith, 1967).

The probe technique used by Posner and Boies had several strong points. First, by presenting probes at various times relative to the sequence of events in the primary task, it was possible to observe changes in the amount of interference, depending on when the probe occurred. Differences in the capacity required by specific mental operations assumed to be taking place at specific times, as opposed to overall task requirements, could then be inferred. Second, since the processes of preparation and encoding were found to take place following the warning signal and the first letter, respectively, changes in probe RTs during those time periods could help clarify the relationship between the three components of attention. Also, by measuring RT on both the primary and the probe tasks, the effects of each task on the other could be easily assessed. Finally, both the letter-matching task and simple reactions have been extensively studied, and a great deal of research is available to which findings about processing capacity may be related.

Posner and Boies (1971) report three experiments on the measurement of processing capacity with the probe technique. The results may be summarized as follows: 
1. Primary task RTs on trials during which a probe response was not required were not significantly longer than RTs on trials on which no probe was presented. Thus, the interference from which the use of processing capacity was inferred occurred in RTs to the probes only.

2. Compared with RTs to probes presented during the ITI, probe RTs were shorter following the presentation of the warning signal. This enhancement of performance on the probe task following a warning signal for the primary task was interpreted by Posner and Boies as the result of nonspecific preparation.

3. Probe RTs did not increase (reflect interference from the demands of the primary task) until about 500 msec. prior to the onset of the second letter. This was true whether the ISI was $500 \mathrm{msec}$. or $1000 \mathrm{msec}$, and whether the first letter was present until $\underline{S}$ made his response or was turned off after $50 \mathrm{msec}$. As is described above, encoding of the first letter, or the processes responsible for the specific advantage on primary task RTs of presenting the two letters sequentially, had been shown to be complete by about $500 \mathrm{msec}$. following presentation of the first letter. Posner and Boies used this evidence to suggest that encoding of a letter required no processing capacity, as they defined the terms. 
4. Reliably longer probe RTs were found to those probes which occurred within $500 \mathrm{msec}$. prior to the second letter and about $300 \mathrm{msec}$. after the second letter. The increase observed at $500 \mathrm{msec}$. before the second letter was not due to the actual appearance of the second letter, because few of the probe RTs were long enough to occur after the second letter. Although their study was not designed to identify the processes producing this interference, Posner and Boies suggested that mental operations following encoding, such as rehearsal of the first letter, generation of its distinctive features to be used in testing against the second letter, and preparing to execute a response, may have required capacity, while the encoding, itself did not.

The experiment to be reported here was designed to clarify the finding of no interference with RTs to probes presented during the period of time when encoding of the first letter was presumably occurring. Although Posner and Boies suggested that the lack of interference indicated the absence of processing capacity requirements for encoding, several alternative explanations seem possible. One is based on the notion that the central processor is a single channel which must switch between separate input sources to handle simultaneous demands for processing 
(Kristofferson, 1967; Swets and Kristofferson, 1970). Perhaps it was possible for $\underline{S}$ s in the Posner and Boies experiment to switch attention to the probe task long enough to do the necessary processing of the probe and still switch back to process the first letter in time to finish encoding it before the second letter appeared. In most of the studies reported by Posner and Boies, the first letter remained present throughout the $1000 \mathrm{msec}$. ISI. Under these conditions $\underline{s}$ could have encoded it at his leisure, taking time out to perform the probe task if necessary. Posner and Boies attempted to check on this possibility by making the exposure duration of the first letter uncertain. When it was turned off randomly after 50 , 150,500 , or 1000 msec., probe RTs were still not significantly interfered with until $500 \mathrm{msec}$. before the second letter, and error rates were very low. If the single channel had been required for both encoding the letter and responding to the probe, then either RT to the probe should have increased while the channel was engaged in encoding, or more errors should have resulted from a failure to register the first letter properly when the channel was switched back to the primary task after processing the probe.

This conclusion is suspect on two grounds. First, 
the nonsignificant differences reported (Posner and Boies, 1971, Fig. 13) are in the direction of greater interference for $50 \mathrm{msec}$. than for $500 \mathrm{msec}$. exposure durations. Second, it is not clear that turning off the letter was successful in actually removing it from the display screen or in preventing $\underline{S}$ from reading the letter from his visual sensory store. Were the letter bright enough against the screen, the image of the first letter may have persisted for a large portion of the ISI, even with only the $50 \mathrm{msec}$. exposure duration (Neisser, 1967; Sperling, 1960).

To further control for the possibility of switching processing away from the primary task to deal with the probe, the present experiment shortened the exposure duration of the first letter to $15 \mathrm{msec}$. and followed it on the screen with a pattern of random dots (Haber, 1970). Such a masking stimulus has been shown to effectively end the representation of a visual stimulus in very short-term visual memory (Averbach and Sperling, 1961; Sperling, 1962). Under these conditions, it was hypothesized that if $\underline{S} s$ did need the single channel to encode a letter, then either RTs to the probes near the first letter would increase while encoding took place, or errors in the letter-matching task would increase on probed trials when the channel could not switch back to the primary task in time to catch the briefly 
presented first letter.

Another possible reason for the lack of interference in the probe RTs near the first letter is derived from a more flexible view of processing capacity. The central processor might be viewed as a system in which capacity can be allocated to simultaneous operations without interference as long as the total capacity required does not exceed some limit at any given point in time (for a similar view, see Moray, 1967). If this were the case, it might be that in the Posner and Boies task the amount of processing space required for encoding the first letter was too small to be detected by the simple RT probe task. That is, encoding the first letter and performing the secondary task simultaneously may not have exceeded the total available central processing capacity. If so, then increasing the complexity of the secondary task, and thus the load it places on the processor, might permit the detection of a small amount of processing capacity used in encoding.

In the present experiment, two levels of probe task difficulty were employed--Donders (1868) type a and type c reactions. Posner and Boies used type a reactions as the probe task in their studies. From work by Ells (1969), it was expected that a type $\subseteq$ reaction would require more processing capacity, as well as more time, than a type a 
reaction. Ells asked Ss to move a lever to the left or right in response to a visual signal. Probe RTs to a tone presented 100 or $150 \mathrm{msec}$. after the visual signal on the primary movement task were longer if the signal could indicate that no movement was required than if the signal always indicated a movement either left or right. Thus, in keeping the overt responses the same but having one signal indicate the inhibition of movement responses, the processing capacity required by the movement task was increased. Similarly, inclusion of a type c reaction in this study was an attempt to increase the load on the limited capacity system and demonstrate interference in probe RTs at the time of encoding of the first letter. 
Method

Subjects

Data were collected from nine female and six male $\underline{S}$. Since one female $\underline{S}$ consistently withheld her responses to the probe until she had responded on the letter-matching task, her data were not included in the final analysis. Lileven of the $\underline{S}$ s were local college students paid $\$ 2.00$ an hour for their participation, and the remaining three were IBM employees. Two $\underline{S}$ s had had at least some previous RT experience, but the other 12 Ss had not participated in a psychological experiment before.

Each $\underline{S}$ was run individually for five one-hour sessions at about the same time of day. Most $\underline{S}$ s had sessions which began after 5:30 PM, but two $\underline{S}$ s began their sessions at 8:00 AM. Due to varying schedules of computer and $\underline{S}$ availability, the number of days elapsing between two consecutive sessions was not constant: $56 \%$ of the separations between sessions were of one day, and $91 \%$ were of a week or less.

\section{Apparatus and Stimuli}

An IBM 1800 computer was programmed to select the stimuli, control the timing sequences in the experiment, and record on magnetic tape the conditions of each trial, along, 
with Ss' $^{\prime}$ responses and RTs. Ss sat at a table facing a Miratel (Ball Brothers, HLB Series) television monitor with a screen size of 11 by $131 / 2$ inches. Since Ss were allowed to sit as they felt most comfortable, and to change posture during the session, viewing distance was variable. ivormally, the viewing distance was between 20 and 35 inches. However, one $\underline{S}$ with poor acuity sat with his eyes about 12 inches from the screen.

The letter stimuli were dark gray on the light gray background of the television screen. The screen was lit by a P4 sulfide phosphor, which decays to $0.1 \%$ of its initial brightness in $20 \mathrm{msec}$. The background luminance was measured using a Spectra Brightness Spot Meter (Model UB 1/4). With the fluorescent lights in the room on, as they were during experimental sessions, the background luminance near the center of the screen was approximately $25 \mathrm{ft}-\mathrm{L}$.

A full alphabet of upper- and lowercase letters was used. Depending on the viewing distance, the uppercase letters subtended a visual angle of between $20^{\prime}$ and $34^{\prime}$ vertically, and $14^{\prime}$ and $24^{\prime}$ horizontally. The lowercase letters differed in size depending on the normal shape of the letter. For example, "s" subtended between $12^{\prime}$ and $20^{\prime}$ of visual angle both vertically and horizontally; "b" was between $20^{\prime}$ and $34^{\prime}$ high, and "m" was between 14' and $24^{\prime}$ wide. 
The center of the television screen was marked at the beginning of each trial with a plus sign the size of the lowercase "s." The plus sign served both as a fixation point and as a warning signal. When the two letter stimuli appeared, their positions were just to the left and right of the plus sign. The stimulus field (letter, plus sign, letter) subtended between $58^{\prime}$ and $1^{\circ} 41^{\prime}$ of visual angle. A visual masking stimulus was constructed such that its border was slightly larger than the largest uppercase letter. It looked like an upright rectangle filled with a random dot pattern and with an extra dot touching the border outside each corner and outside the center of each side of the rectangle.

Bursts of white noise, 50 msec. in duration, were produced by an H. H. Scott Random Noise Generator (Type 811-B) and presented by means of Sharpe HA-8 stereo headphones. Although no sound pressure measurements were made, all Ss found the noise bursts clearly audible.

Subjects responded by depressing one of three buttons on a small metal box. S's left index finger rested on the left button, which was used for responses to the noise. The center and right buttons were used for "same" and "different" letter-matching responses, which were made with the right index and second fingers, respectively. 
Primary and Probe Tasks

As did Posner and Boies (1971), the present study employed two tasks--a primary letter-matching task and a secondary probe task. In the letter-matching task, $\underline{S}$ was required to respond "same" or "different" on the basis of the names of two letters presented visually. As was true for several of the conditions used by Posner and Boies, no match involved a pair of physically identical letters. The first letter was always uppercase and appeared to the left of the fixation point; the second, which was always lowercase, appeared to the right of the fixation point. As is shown in Table 1 , the following sequence of events made up one trial of the letter-matching task:

1. An intertrial interval (ITI), during which the television screen was blank, preceded each trial. The duration of the ITI was randomly varied between four and six seconds.

2. The plus sign came on in the center of the screen as a warning signal and fixation point; it remained present for 500 msec.

3. As the warning signal went off, the first letter was briefly flashed just to its left. The duration of the first letter was approximately $15 \mathrm{msec}$

4. On some blocks of trials (the Mask Condition) the 
Table 1

Time in Milliseconds of Primary and Probe Task Events

\begin{tabular}{|c|c|c|c|c|}
\hline \multicolumn{3}{|c|}{ Primary Task } & \multicolumn{2}{|c|}{ Probe } \\
\hline Event & Onset & Offset & Number & Onset ${ }^{a}$ \\
\hline Intertrial interval & $\begin{array}{l}-6000 \text { to } \\
-4000 b\end{array}$ & 0 & 1 & -2000 \\
\hline Warning signal & 0 & 500 & $\begin{array}{l}2 \\
3\end{array}$ & $\begin{array}{r}0 \\
400\end{array}$ \\
\hline First letter & 500 & 515 & 4 & 500 \\
\hline Mask & 600 & 800 & $\begin{array}{l}5 \\
6\end{array}$ & $\begin{array}{r}600 \\
1300\end{array}$ \\
\hline Second letter & $\begin{array}{l}1500 \text { or } \\
1700\end{array}$ & $\begin{array}{l}\text { With S's } \\
\text { primary } \\
\text { task re- } \\
\text { sponse }\end{array}$ & 8 & 1700 \\
\hline
\end{tabular}

Feedback events (times from the primary task response)

Primary task RT

\begin{tabular}{l|l|l}
200 & 1200 \\
1700 & 2450 \\
1700 & $\begin{array}{l}\text { With S's } \\
\text { probere- } \\
\text { sponse }\end{array}$ \\
\hline
\end{tabular}

ilote.... The onset of the warning signal is called time 0 .

a. Probes were $50 \mathrm{msec}$. in duration.

LIIs werc randomly determined between 4 and ó seconds. 
visual noise mask was presented for $200 \mathrm{msec}$. following the offset of the first letter and in the same position. 5. Either 1000 or $1200 \mathrm{msec}$. after the onset of the first letter, the second letter appeared to the right of the fixation position. This lowercase letter remained present until $\underline{S}$ made his response.

6. When $\underline{S}$ had pressed one of the two primary-task response buttons, indicating "same" or "different," the second letter disappeared; $200 \mathrm{msec}$. later, feedback was displayed in the upper lefthand corner of the screen, well away from the stimulus presentation area. The feedback was a number indicating the speed in msec. of S's same-different response, given he had responded correctly. When the response was incorrect, the number "l" appeared instead of the RT. The duration of the feedback display was $1000 \mathrm{msec}$.

7. If $\underline{S}$ had completed the secondary task (as described below), the ITI began with the offset of the feedback. Otherwise, the ITI began with $\underline{S}^{\prime} s$ probe response. After all the experimental sessions had been completed, two difficulties with the timing sequence for the primáry task were discovered. First, it was intended that the ISI, the interval between the onset of the first letter and the onset of the second letter, always be 1000 
msec. This was true for all blocks of trials in which no visual mask followed the first letter (the No Mask Condition). However, due to an error in the program controlling the timing of the stimulus events, only those Mask Condition trial blocks which came at the beginning of a session had the ISI equal to $1000 \mathrm{msec}$. For all Masked trial blocks which were preceded by a No Mask trial block, the ISI was $1200 \mathrm{msec}$. This resulted in $3 / 8$ of the data (or $3 / 4$ of the Mask Condition data) being collected with a $1200 \mathrm{msec}$. ISI. Subjective reports from all Ss and from $\underline{E}$, who ran for many sessions herself, did not indicate any perception of the different ISIs. It was an irregularity in the experimental results which led to the discovery of the discrepant ISIs.

T'he second unfortunate feature of the timing concerned the duration of the two blank intervals between the warning signal and the first letter, and between the first letter and the mask. It was intended that these intervals be as short as possible, that is, that there be a minimum of time during which the screen was blank immediately following the offset of the plus sign and the offset of the first lettér. Although it was not possible to measure the actual durations of events on the television screen, two photographs of an oscilloscope measuring electrical input to the 
screen suggested that the blank intervals in both cases were between 75 and $100 \mathrm{msec}$. long.

The secondary or probe task involved key-press responses with the left index finger to $50 \mathrm{msec}$. bursts of white noise. There were two versions of the noise task. In the single ear condition (E Condition), all the noise bursts were presented to S's right ear and the response required was a Donders ( 1868 ) type a reaction, that is, a simple button press to each noise burst. The double ear condition (EE Condition) required a Donders type $\underline{c}$ reaction. Noise bursts could occur in either the right or the left ear, but $\underline{S}$ was to press the noise button only to noises coming to his right ear.

A single noise probe was presented during half of the trials on the letter-matching task. As is shown in Table I, the probe could occur at any one of eight positions relative to the sequence of events in the primary task. Numbering the probe positions from the beginning of the trial and calling the onset of the warning, signal time 0 , the noise probes bagan at the following times: (I) minus 2000 msec.--during the ITI, two seconds prior to the onset of the warning signal; (2) $0 \mathrm{msec}$--simultaneously with the warning signal onset; (3) $400 \mathrm{msec}--100 \mathrm{msec}$. prior to the onset of the first letter; (4) $500 \mathrm{msec}$--simultaneously 
with the first letter; (5) $600 \mathrm{msec} .-100 \mathrm{msec}$. after the first letter; (6) 1300 msec.; (7) $1500 \mathrm{msec}$; and (8) 1700 msec. When the ISI was $1000 \mathrm{msec}$, probes 6,7 , and 8 came $200 \mathrm{msec}$. before, at the same time as, and $200 \mathrm{msec}$. after the second letter, respectively. When the ISI was $1200 \mathrm{msec}$, probes 6, 7, and 8 came $400 \mathrm{msec}$. before, 200 msec. before, and at the same time as the second letter. If $\underline{S}$ had not responded to a noise burst in his right ear by $500 \mathrm{msec}$. after the time the primary task feedback went off, he was prompted by the word "Noise?," which appeared in the upper lefthand corner of the screen. Pressing the noise button then erased the prompt and began the timing of the ITI. In the EE Condition, if $\underline{S}$ had pressed the noise button following a noise burst in his left ear, the words "Wrong Noise" were displayed $500 \mathrm{msec}$ after the feedback had gone off. The wrong noise reminder remained present for $750 \mathrm{msec}$, after which the timing of the ITI was begun.

Thirty-two trials on the letter-matching task made up one treatment block. On each trial, the first letter was randomly selected from the set of uppercase letters. Half the trials were "same" trials, in which case the second letter was the lowercase version of the first letter. On "different" trials the second letter was 
randomly selected from the set of lowercase letters, excluding the first letter. Within both the 16 "same" and the 16 "different" trials, noise probes occurred on half the trials, once in each of the eight probe positions. Thus, at the end of a block of trials, $\underline{S}$ had provided 32 letter-matching RTs and had heard 16 noise probes, two in each probe position. In the $\mathrm{E}$ Condition $\underline{S}$ responded to all 16 noise probes presented in one trial block. In the EE Condition, right and left ear probes were selected at random for the first of two blocks of trials, and the ear of presentation assignment was reversed for the second block. Thus, $\underline{S}$ responded to an average of eight noise probes in one EE Condition trial block; two blocks provided probe RTs on "same" and "different" trials for each of the eight probe positions.

Design and Procedure

The two conditions of the letter-matching task (No Mask and Mask) and of the probe task (type a and type $\underline{c}$ reactions) were combined in four treatment conditions, which were identified as follows: (1) NM-E, (2) NM-EE, (3) $M-E$, and (4) $M-E E$. Each session consisted of two consecutive trial blocks of each treatment. The first day of the experiment was considered practice, and all 
Ss received treatment blocks in the order in which they are identified above $(1-2-3-4)$. On days two through five, the four treatments were administered in Latin-square order for each $\underline{S}$. A single $4 \times 4$ Latin square was selected such that across rows each treatment followed each other treatment exactly once. The following rows represented the treatment presentation orders for the four experimental days: $3-2-1-4,1-3-4-2,2-4-3-1$, and 4-1-2-3. Although all Ss experienced the same four treatment orders, two Ss received order $3-2-1-4$ on day two and the remaining three rows in order on days three through five, and four $\underline{S} s$ started with each of the other three orders, returning to the first row after completing the fourth.

The instructions read to each $\underline{S}$ before his first session in the experiment are reprinted in Appendix A. Both the letter-matching task and the probe task were described fully and any questions about procedure were answered. Emphasis was placed on speed and accuracy in the letter-matching task. Ss were told that the purpose of the noise task was "to make things a little harder" and that, while they should respond as rapidly as possible to the noise, they should try not to let their noise responses affect their speed and accuracy on the lettermatching task. 
Feedback on the primary task was provided in each of three ways. In addition to the individual RTs displayed after each trial, mean RT and the number of correct responses out of 32 were displayed at the end of each block of trials. No feedback was given concerning speed on the probe task.

Before the start of each trial block, the conditions of that block were identified by a message (e.g., "No Mask - E") in the upper lefthand corner of the screen. $\underline{S}$ was allowed to remove the headphones and rest as long as he felt was necessary between trial blocks. He initiated each trial block by pressing the noise button, which removed the identification message and started the timing of the first ITI. 
Results

The basic results are of three types--error rates, RTs on the probe task, and RTs on the letter-matching task. Each of these measures may be considered as a function of probe position and experimental condition--Mask (M) vs. No Mask (NM) and Type a (E) vs. Type $\underline{c}$ (EE) probe task. As was described above, part of the Mask Condition data was collected with an ISI of $1000 \mathrm{msec}$ and part with an ISI of $1200 \mathrm{msec}$. With the longer ISI, probe positions 6 , 7 , and 8 were at different times relative to the second letter. Therefore, in the analyses to follow, only the first five probe positions are considered for the Mask Condition. Data from the No Mask Condition alone are used in analyses involving all eight probe positions. When the results were considered separately for each of the four experimental sessions, no consistent practice effects were found. Within one session, RTs tended to be faster on the first two blocks of trials, and variability of RTs greater on the later blocks, but again, the pattern of results revealed no consistent differences related to experimental conditions. Therefore, in order to avoid estimating data for $\underline{S}$ s wose discarded error trials left empty cells when sessions and trial blocks were kept 
distinct, the results below are collapsed across sessions and trial blocks.

In all the analyses of variance and contrasts, the error term used to test an effect is the interaction of that effect with Ss. Scheffé's multiple comparison method was used for all the contrasts (see Myers, 1966).

\section{Error Trials}

Data were collected on 14,336 trials (256 in each of four sessions for 14 Ss). The distribution of trials across experimental conditions may be found in Appendix B-I. Of all the trials, 10.2\% were considered errors and were excluded from the analysis of RT. The conditions under which trials were called erroneous and the percentage of the total trials which were discarded due to each type of error are as follows: the letter-matching response was "same" when the letters were actually different, or vice versa, $6.91 \%$; the letter-matching $\mathrm{RT}$ was longer than two seconds or less than $100 \mathrm{msec}, .23 \%$; a probe response was made to a noise burst in the left ear, $1.69 \%$; and the probe RT was longer than two seconds or was made after a "Noise?" prompt, .81\%. The remaining .56\% of the trials were called erroneous for more than one of these reasons. More types of errors were possible in the EE Condition; 
its overall error rate was $10.7 \%$, as compared with $9.6 \%$ for the E Condition. Mask and No Mask had identical overall error rates. Error data for each probe position are included in Appendices $\mathrm{B}-2$ and $\mathrm{B}-3$. Combining the data from all 14 Ss, the total number of errors from the 16 trials at each probe position in the No Mask $E$ and $E E$ Conditions is shown in Fig. 1. Errors on the lettermatching task and errors on the probe task are plotted separately. An analysis of variance on the number of errors from any source in the NM Conditions across all eight probe positions indicated significant effects of probe task $(F=9.02 ; \underline{d f}=1,13 ; \underline{p}<.025)$, probe position $(\mathrm{F}=14.97 ; \mathrm{df}=7,91 ; \mathrm{p}<.001)$, and the task by probe position interaction $(F=3.28 ; \mathrm{df}=7,91 ; \mathrm{p}<.01)$.

It can be seen in Fig. I that there tended to be an increase in errors when a probe came on simultaneously with the warning signal or the first letter, or near the onset of the second letter. Because so many Ss made no errors with probes in certain positions, Wilcoxon matchedpairs signed-rank tests (see Runyon and Haber, 1971) were used to compare the number of errors between pairs of the first five probe positions. Although there were both more probe errors and more letter-matching errors when probes occurred in position 2 than in position 1, this difference 


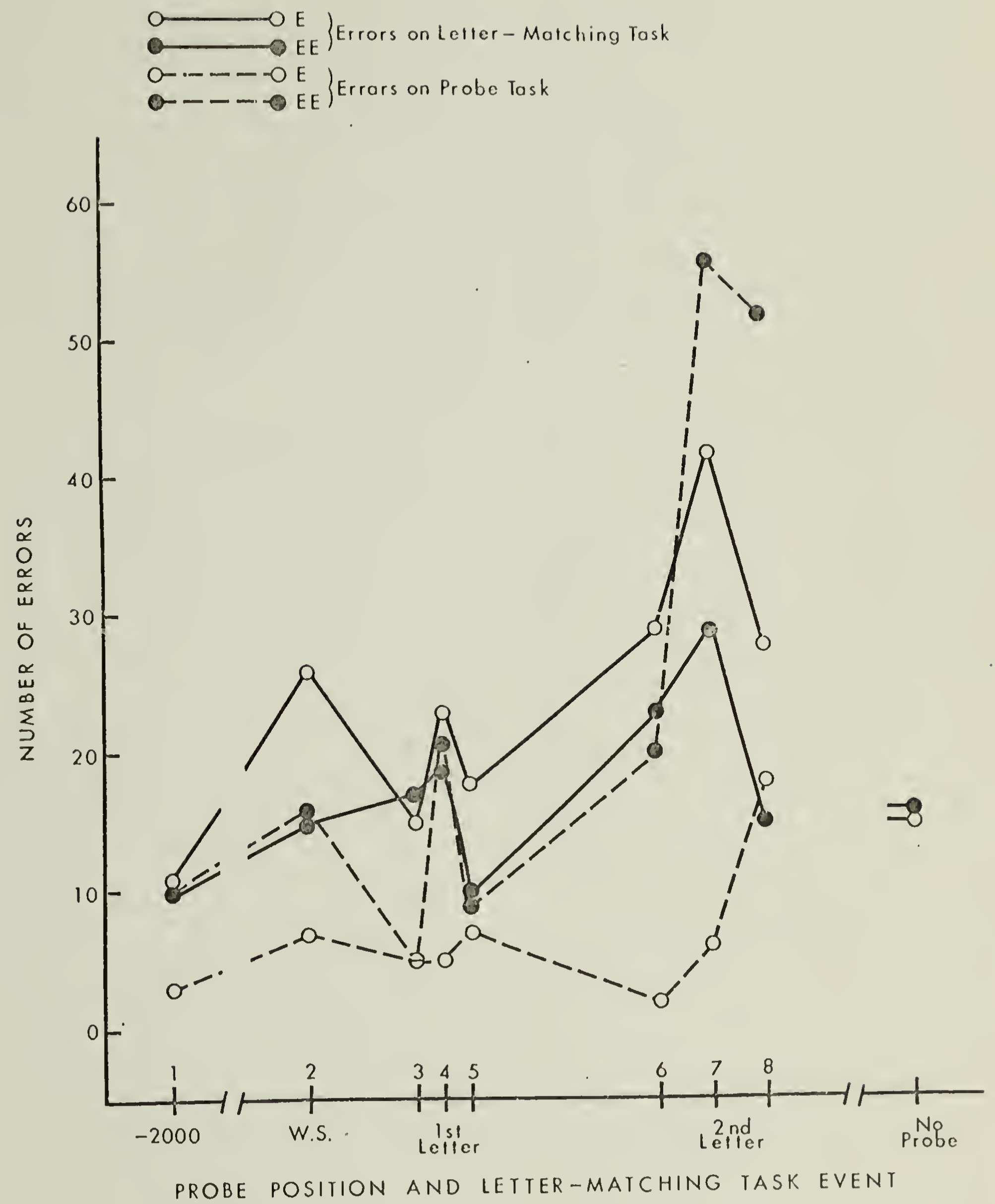

Fig. 1. Number of errors on the letter-matching and probe tasks under No Mask Conditions as a function of probe position. 
reached significance only for letter-matching errors in the $\mathrm{E}$ Condition $(\mathrm{T}=12 ; \mathrm{p}<.02)$. For all conditions except probe errors in the $\mathrm{E}$ Condition, there was a tendency for probes presented simultaneously with the first letter to result in more errors than probes in positions 3 and 5. However, the only significant differences were in the EE Condition when comparing probe errors between positions 3 and $4(\mathrm{~T}=10.5 ; \underline{\mathrm{p}}<.0 \mathrm{I})$ and positions 4 and $5(\mathrm{~T}=17 ; \underline{\mathrm{p}}<.05)$, and when comparing letter-matching errors between positions 4 and $5\left(T=24.5 ; \mathrm{p}^{<} .10\right)$.

Another observation of interest concerns the 243 errors resulting from probe responses to noise bursts in the left ear. More of these wrong noise responses (135) occurred on "same" trials than on "different" trials. Thus, Ss were more likely to respond to a wrong noise probe when doing so meant making both responses with index fingers than when it meant making one response with the left index finger and the other with the right second finger. Also, 145 of these errors occurred when probes came on in positions 7 and 8 , near the onset of the second letter. Inhibiting a response to the probe seems to have been more difficult when $\underline{S}$ s were at the same time preparing to respond on the letter-matching task. 
Probe RTs

Before RTs over $2000 \mathrm{msec}$. were discarded, probe RTs pooled across all observations displayed a positively skewed distribution with a mean of $697 \mathrm{msec}$. and a median of approximately $542 \mathrm{msec}$. There were no premature probe R'Ts of less than $150 \mathrm{msec}$.

The curves in Fig. 2 show mean probe RTs for the four experimental conditions as a function of probe time relative to the letter-matching task. Each point is the mean of 14 individual S scores, which were obtained by taking the arithmetic average of all the probe R'Ts on nonerroneous trials for a given condition and probe position, regardless of session or trial block. The maximum number of observations contributing to a given S's scores was 16 in the $E$ Conditions and 8 in the EE Conditions, but these totals were depleted by errors. Mean probe RTs, along with the standard deviations and standard errors of the means, appear in Appendix B-4. In general, variability of the probe RTs tended to increase with later probe presentations.

Several interesting findings are evident from the probe RTs plotted in Fig. 2. First, the effect of increased probe task difficulty was to add a constant of approximately $117 \mathrm{msec}$. to the probe RTs under the E 


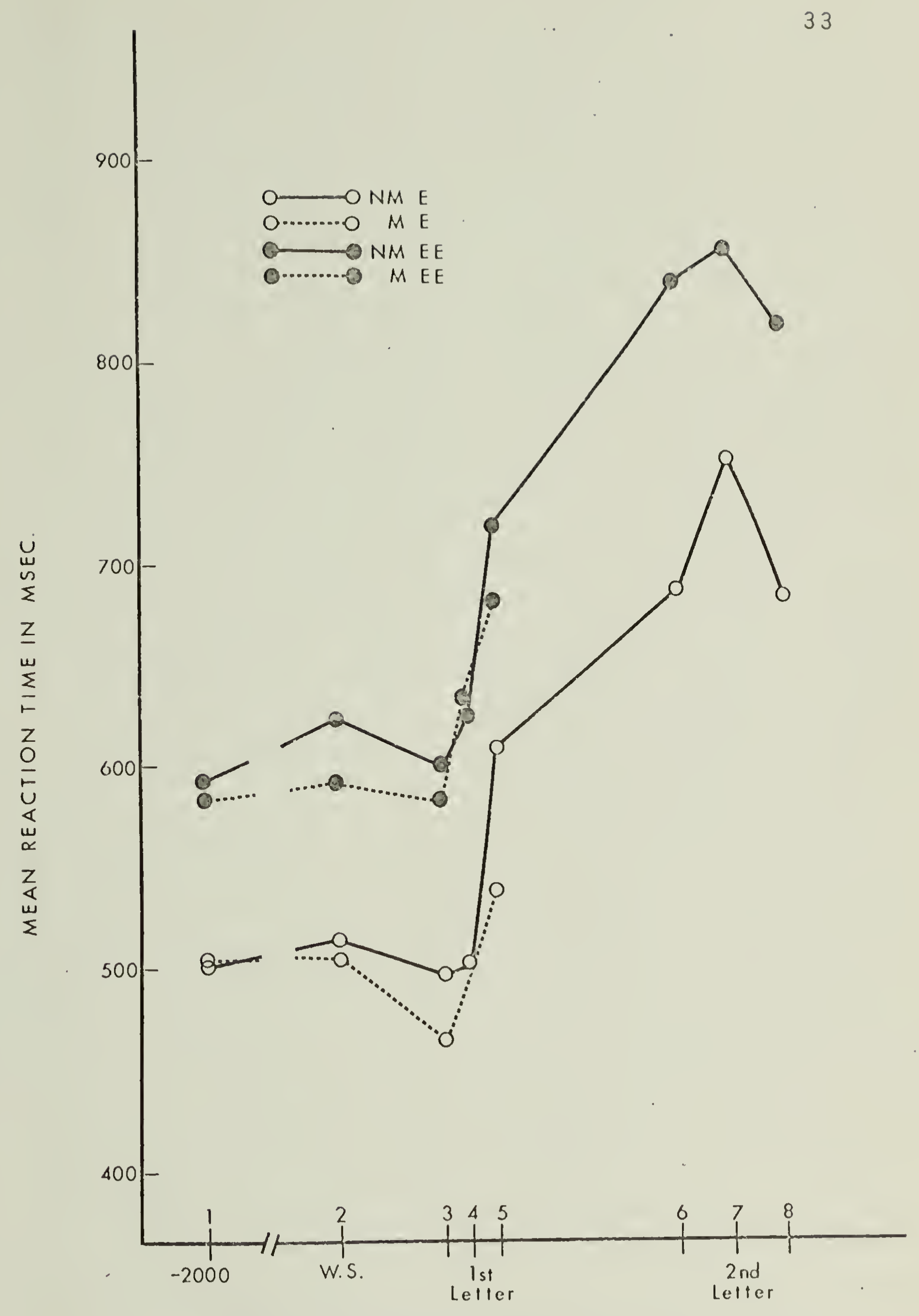

PROBE POSITION AND LETTER-MATCHING TASK EVENT

Fig. 2. Probe RTs as a function of the position of the probe relative to the events in the letter-matching task. 
Condition. Analysis of the NM data over all eight probe positions showed a highly significant effect of probe task $\left(F=60.31 ; \mathrm{df}=1,13 ; \mathrm{p}^{<.001)}\right.$, which did not interact with probe position $(F<1)$. Similar results were found when the $M$ Condition data were included and the first five positions were submitted to an analysis of variance. Again, the main effect of $E$ vs. EE was significant ( $F=72.96 ; \underline{d f}=1,13 ; \mathrm{p}^{<}$ $.001)$, but none of the interactions of secondary task level With masking condition or probe postion reached significance. Although probe task difficulty and probe position did not interact significantly, Fig. 2 indicates that the difference between NM-E and NM-EE Conditions did tend to be greater at the later probe positions. The mean difference scores for each of the eight probe positions are as follows: 92, 108, 104, 124, 110, 154, 105, and $136 \mathrm{msec}$. (Standard deviations and standard errors may be found in Appendix B-5.) The great variability of these difference scores resulted in the lack of a significant interaction. The main effect of masking the first letter was assessed by considering only data from the first five probe positions. Although probe RTs tended to be faster on Mask trials with an ISI of $1000 \mathrm{msec}$, this finding was confounded with the fact that data from Mask Condition trials with a $1000 \mathrm{msec}$. ISI were always collected first 
in an experimental session. Since the overall pattern of results for $1000 \mathrm{msec}$. ISI and $1200 \mathrm{msec}$. ISI was similar,

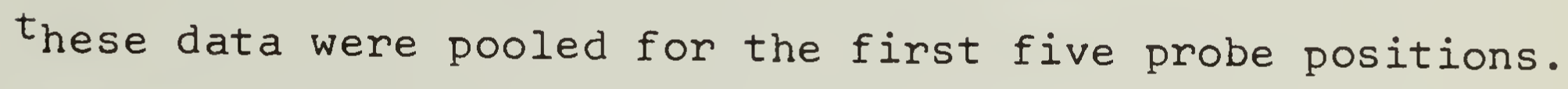
When this was done, probe RTs in the Mask Condition were faster than in the No Mask Condition ( $F=9.35 ; \mathrm{df}=1,13$; $\mathrm{p}^{<.01)}$. It was expected that masking the first letter might make the task more difficult and hence possibly raise probe RTs. That probe RTs were instead faster on

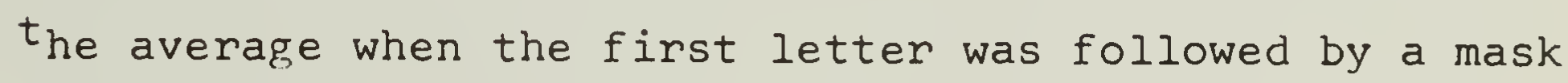
may somehow be the result of the longer ISI for that condition.

The main effect of probe position was highly significant both across all probe positions for the NM data ( $F=24.2$; $\mathrm{df}=7,91 ; \mathrm{p}^{<.001)}$ and across the first five probe positions for the data from $M$ and $N M$ Conditions combined $(F=8.93$; $\underline{\mathrm{df}}=4,52 ; \mathrm{p}^{<.001)} . M$ and $\mathrm{NM}$ Conditions had different effects On probe RTs depending on when the probe occurred. This is evidenced by significant interactions between masking condition and probe position across the first five probe positions $\left(F=3.086 ; \underline{d f}=4,52 ; \underline{p}^{<.05}\right)$ as well as positions 3,4 , and $5(F=3.592 ; \underline{d f}=2,26 ; \underline{p}<.05)$.

A series of contrasts was done to determine the locus of the probe position effect. One interesting observation is that in these results there is no evidence for the pro- 
cess Posner and Boies call nonspecific preparation. That is, there was no significant decrease in probe RTs following the warning signal but prior to the first letter. None of the contrasts among positions 1, 2, and 3 reached a level of significance above .20.

Of most interest to the question of the encoding of the first letter are the probe RTs at positions 3, 4, and 5. Looking only at the NM results, positions 3 and 5 $\left(F=18.24 ; \mathrm{p}^{<.025)}\right.$ and 4 and $5\left(F=29.8 ; \mathrm{p}^{<.001)}\right.$ were found to differ, but positions 3 and 4 did not $(F<1)$. Thus, under conditions of no mask, the probe RTs did not begin to show differential interference from events in the lettermatching task until $100 \mathrm{msec}$. after the presentation of the first letter. None of the interactions of the contrasts with secondary task level was close to being significant.

In the Mask Condition alone, a slightly different pattern of results was obtained. Here the R'Is to probes presented simultaneously with the first letter (position 4) did reflect some interference from the letter-matching task. The contrast between probe RTs at positions 3 and 4 was significant $\left(F=14.5 ; \mathrm{p}^{<.005)}\right.$, as was the contrast between 3 and $5\left(F=14.5 ; \mathrm{p}^{<.025)}\right.$. However, in the $M$ Condition, probe RTs at positions 4 and 5 did not differ significantly $(F=5.15 ; p>.20)$. As in the NM data, none 
of the interactions of the contrasts with type of secondary task was significant.

R'l's on the Letter-Matching Task

The distribution of times to respond "same" or "different" on the letter-matching task was positively skewed with a mean of $392 \mathrm{msec}$. and a median of approximately 361 msec. On only six trials were RTs two seconds or longer. Although $28 \mathrm{RTs}$ of less than $100 \mathrm{msec}$. were recorded, all but three of these were the result of holding down the button prior to the presentation of the second letter. "Same" responses were on the average about 80 msec. faster than "different" responses. Since the two response types were confounded with the finger used to make the response and with the finger on the opposite hand used to make probe responses, no same-different distinction is made in the results to follow.

Fig. 3 shows the pattern of RTs on the primary letter-matching task in the NM Condition as a function of the time in the trial at which the probe occurred. Trials on which no probe was presented are grouped together and plotted on the righthand side of Fig. 3. Also plotted are the letter-matching RTs from those trials in the NM-EE Condition on which a probe was presented in the left ear; 


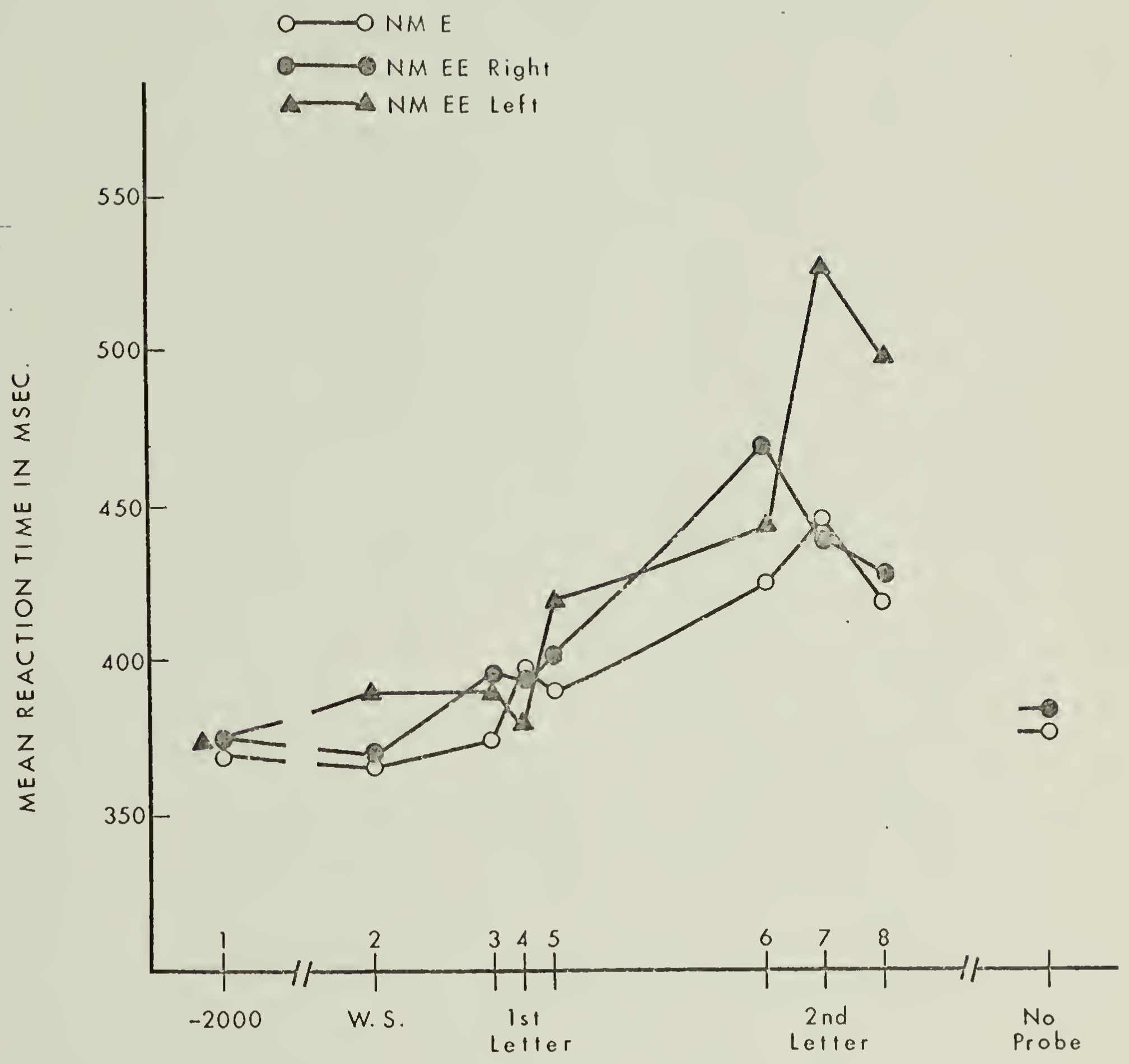

PROBE POSITION AND LETTER-MATCHING TASK EVENT

Fig. 3. RTs on the letter-matching task under No Mask Conditions as a function of probe position. 
that is, the probed trials on which $\underline{S}$ was to withhold his probe response ${ }^{l}$. Mean letter-matching RTs for all the conditions are in Appendix B-6.

The main effects of mask condition and secondary task condition were not significant in any of the analyses involving letter-matching RTs for trials on which probe responses were also made. However, when probes were presented to the left ear, the letter-matching RTs were faster in the Mask Condition than in the No Mask Condition ( $F=5.11$; $\mathrm{df}=1,13 ; \mathrm{P}^{<.05)}$. This result may reflect the longer ISI employed for $3 / 4$ of the Mask data.

No significant increases in primary task RTs were found as a result of probe presentations in the first five positions. Probing in positions 6,7 , and 8 did interfere with letter-matching RTs, however. Looking at the NM data for trials on which probe responses were made, lettermatching R'I's with probes in positions 6, 7, and 8 were longer than RTs with probes in positions 3, 4, and 5 (F= $16.08 ; \mathrm{p}^{<.10)}$. Contrasts were also significant between RTs with probes in position 5 vs. $6\left(\mathrm{~F}=37.66 ; \mathrm{p}^{<.001}\right)$ and

In the NM Condition with left ear probes, it was necessary to estimate one score for each of two Ss, because all observations for the cell were errors. One $\underline{S}$ had an empty cell at probe position 7 and the other at position 8 . In analyses involving these scores, 2 degrees of freedom were subtracted (see Myers, 1966). 
6,7 , and 8 vs. the non-probed trials $(F=33.54 ; \mathrm{p}<.001)$. In the NM Condition when probes were presented to the left ear and no probe response was required, probe positions 6,7 , and 8 were significantly higher than position $1(\mathrm{~F}=32.5 ; \mathrm{p}<.001)$; positions 5 and 6 did not differ ( $F=$ $2.35 ; \mathrm{p}>.20)$. Thus, in primary task RTs, substantial interference occurred only when probes were presented near the time of the second letter. RTs remained flat with probes in the first five positions. 
Discussion

The major issue addressed in this study concerned the requirements for processing capacity from the operations performed by $\underline{S}$ in a letter-matching task. In particular, the study was designed to investigate the conclusion of Posner and Boies (1971) that the initial encoding of a letter does not take capacity. Several lines of evidence in the results reported here support the opposite conclusion, that is, that encoding does require capacity. This evidence takes the form of interference as a result of performing operations on the probe task simultaneously with the encoding of the first letter.

Posner and Boies did not state a model of processing capacity except to assume that operations requiring capacity would tend to interfere with each other. Although no specific model underlay the present study, it was pointed out in the introduction that the experimental variations employed here were suggested by two notions about the operation of a central processor. A single-channel switching model assumes that only one task may be attended to at a time and that processing operations on two tasks must occur, or at least be initiated, successively (see Kristofferson, 1967; Smith, 1967; Schvaneveldt, 1969). 
Shortening the duration of the first letter and following it with a visual mask were attempts to control for the Possibility that $\underline{S} s$ in the Posner and Boies study could switch attention away from the letter-matching task to process the probe and switch back again with time left to encode the first letter. A "variable allocation" model suggests that attention is not necessarily switched between tasks in an all-or-none fashion, but rather that processing capacity may be allocated to operations on more than one task simultaneously without interference as long, as the total capacity required does not exceed some limit (see Moray, 1967). Employing a more difficult probe task was an attempt to increase the load on the central processor such that processing the probe at the same time as encoding the letter would be more likely to exceed the available capacity. In discussing the present study, an attempt will be made to relate the results to these general models about the way a central processing capacity mechanism might operate.

In the NM-E Condition, which was most similar to the situation employed by Posner and Boies, and in the NM-EE Condition, probe R'Ts showed no evidence of interference from encoding the first letter. No increase in probe RTs was detected until $100 \mathrm{msec}$. following the first letter 
(probe position 5). Although this interference occurred earlier in the trial than in the Posner and Boies study, it is consistent with a recent report by Posner and Klein (1971) that interference in probe RTs began sooner after the onset of the first letter the shorter the exposure duration of that first letter. The shortest exposure duration used by Posner and Klein was $50 \mathrm{msec}$. In that case, probes at the offset of the first letter showed no interference, but probes $150 \mathrm{msec}$. after the onset of the first letter did show interference. With longer durations of the first letter $(150,500$, and $1000 \mathrm{msec})$, no interference was found at probe positions $150 \mathrm{msec}$. after the onset of the first letter.

The results of Posner and Boies, Posner and Klein, and the No Mask Conditions of the present study all failed to show that encoding of the first letter used processing. capacity, as measured by increased probe RTs. One possible explanation for these results is that the necessity for rehearsal of the first letter, or specific preparation for matching it to the second letter, was responsible for the interference which began after the offset of the first letter. Encoding without the use of capacity may still have always occurred immediately upon presentation of the first letter. However, the results from the lask Condi- 
tion suggest another interpretation. When the first letter was followed by a mask, an increase was found in RTs to probes presented simultaneously with the first letter. It seems unlikely that rehearsal was responsible for the interference at the time of the presentation of the first letter. Instead, masking the first letter may have been successful in forcing, Ss to begin encoding that first letter as soon as it came on. Under this interpretation, the No Mask Condition and the conditions employed by Posner and Boies and by Posner and Klein may have allowed time for Ss to switch attention to begin processing on the probe task and still return to the primary task in time to encode the first letter before it disappeared from the screen or from short-term visual store.

For this single-channel explanation to account for the data, it must be assumed that the Posner and Boies estimate for the duration of the complete encoding process is not also the length of time for which encoding demanded full use of the limited capacity channel. Even $200 \mathrm{msec}$. would be too long, considering the fact that the rise in probe R'I's with masked presentation of the first letter was only about $45 \mathrm{msec}$. It may be that an incoming signal, in this case either the letter or the noise, need only be processed partially until enough information is obtained for use by 
the remaining processes; then the channel could switch to initiate encoding on the remaining task demanding its attention.

If a more flexible mechanism of limited capacity were assumed, then it may be that encoding of the first letter and encoding of (or initiating processing on) the noise probe were occurring in parallel under the Mask Condition. With this interpretation, since both operations required capacity and received less than the full amount, processing was slowed down. Alternatively, processing of the probe and encoding of the letter may have been occurring at the same relative times in both the Mask and the No Mask Conditions, but presenting a mask may have changed the nature of the encoding such that it required more capacity.

Other evidence for interference as a result of the onset of the first letter can be seen in the number of errors made at each probe position. The data suggest that more errors occurred on both the probe task and the lettermatching task when the probe was presented simultaneously with the first letter (position 4). This result would not be expected if encoding required no capacity, because in that case processing a probe would not be detracting from the processing of the letter nor vice versa. With a single-channel processor, increased errors could be the 
result of switching attention to process the probe, thus missing or misreading the first letter, or maintaining, attention on the encoding of the first letter with the effect of either missing the probe or failing to distinguish right and left ear presentations. With variable allocation of capacity, more errors might be due to inadequate processing as a result of sharing an insufficient amount of capacity.

When probes were presented simultaneously with the warning signal (position 2), there also tended to be more error trials, particularly on the letter-matching task. A probable explanation for this finding is that, given probes in position 2 , the actual probe responses occurred, on the average, $511 \mathrm{msec}$. and $608 \mathrm{msec}$. later for $E$ and EE Conditions, respectively. These times are very close to the onset time of the first letter. If executing, a response took capacity, probe responses made near the first letter may have resulted in failures to correctly encode that first letter.

Both the single-channel switching model and the more variable allocation model seem about equally able to account for the increased errors and the results of masking, the first letter as evidence that encoding required capacity. However, the finding that the effect of increasing, the 
difficulty of the probe task did not change with probe position is difficult to explain with a model in which variable amounts of capacity can be allocated to tasks at any time, depending on their demands. Since Ells (1969) showed that more attention was required in a task when a stimulus was included which could signal the withholding of a response, it was expected that type $\subseteq$ reactions would require more capacity that type a reactions. If this were true, then according to the variable allocation model, type $\subseteq$ reactions (EE Conditions) should have reflected more interference from the primary task than did type a reactions (E Conditions). In the present study, no interaction was found between level of difficulty of the probe task and the position at which the probe occurred; that is, type $\subseteq$ reactions were always about $117 \mathrm{msec}$. slower than type a reactions, regardless of the amount of interference those reactions were detecting from the lettermatching task. To save the variable allocation model without adding post hoc assumptions, it would seem necessary to support the unlikely hypothesis that in this particular situation the type $\subseteq$ reactions required only more time and not more processing capacity than the type a reactions.

The lack of interactions between probe task difficulty and probe position is not a problem for the single-channel 
model because the delay in the probe $\mathrm{RT}$ which results when the central channel is engaged in operations on the letter-matching task should be the same, regardless of $t_{\text {he }}$ difficulty of the probe task.

In addition to the results indicating that encoding of a letter required capacity, a number of other findings are notable. By far the largest interference effects detected as a function of probe position can be ascribed to response processes. In addition to the suggestion that probes occurring with the warning signal resulted in more errors on the letter-matching task because of the capacity used in responding, there were several other instances of increased interference from processes associated with responding. Probes presented in positions 6,7 , and 8 , at which times motor preparation or other processes to optimize execution of the letter-matching response were presumably occurring, gave rise to longer probe RTs, longer letter-matching. RTs, and more errors. That this interference was due to response processes is suggested by three other characteristics of the results. First, in the error data, there was a much greater increase in the number of errors made to probes near the second letter in the EE Condition than in the E Condition. This increase was largely the result of more responses to left ear probes. 
It seems to have been difficult for $\underline{S}$ s to withhold a probe response at the same time that they were making a letter-matching response. This is also indicated by a greater increase in letter-matching RTs at positions 7 and 8 when left ear probes were presented (no response was required) than when right ear probes were presented (and a response was required). In addition, more wrong noise responses occurred on same trials than different trials, suggesting that depressing the index finger of the left hand was a harder response to withhold when the index finger of the right hand was also being depressed than when the second finger of the right hand was being depressed.

Aside from the interference from which capacity requirements of response processes and encoding were inferred, the absence of interference at probe position 3 is of interest. This study gave no conclusive evidence for a decrease in RT as a result of nonspecific preparation or general alertness, although the difference between probe RI's at positions 2 and 3 was in the right direction. This may be due to intertrial intervals which were not variable enough in duration for alertness to lapse between trials. It is also possible that the appropriate probe position was not tested in this study; that is, a probe between 
positions 2 and 3 may have resulted in lower probe RTs than at either position 2 or 3 , especially if position 3 were close enough to the presentation of the first letter that probe RT's were beginning to be affected by the encoding of the first letter.

The lack of increased RTs to probes at position 3 also indicates that, if encoding required capacity, then it was not detracting in a measurable way from the processes occurring in the probe task $100 \mathrm{msec}$. after the presentation of the noise and at least $400 \mathrm{msec}$. prior to the execution of the probe response. It is consistent with the data from this study to suggest that in the probe task only encoding and response processes required capacity, but that there was a time interval in the middle of the reaction time to the probe during which processing on the probe task did not require capacity.

The source of interference resulting from probes presented $100 \mathrm{msec}$. after the second letter (position 5) is not clear. It may be that processes in the letter-matching task, such as rehearsal of the encoded form of the first letter, maintainance of its physical characteristics, or generation of the lowercase form, required capacity which delayed or slowed down processing of the probe. It is also possible that responses to the probes in position 5 
came so close to the onset of the second letter that motor preparation, or some other process associated with getting ready to receive the second letter or to respond on the letter-matching task, interfered with the response phase of the probe task. Consistent with this interpretation is the finding that probe RTs at position 5 were lower in the Mask Condition, where the ISI was $200 \mathrm{msec}$. longer, than in the No Mask Condition.

Another curious result is that, although the lettermatching RTs were comparable in speed to performance of that task alone (Posner and Boies, 1971; Posner, Boies, Eichelman, \& Taylor, 1969), RTs on the probe task were very long. It is generally reported that when type a auditory reactions are the sole task for $\underline{S}$, the reaction times after practice for young adults are about 140 to 150 msec. Type $\subseteq$ reactions may take anywhere from 20 to $200 \mathrm{msec}$. longer than simple reactions, depending on experimental conditions (see Woodworth, 1938; Woodworth and Schlosberg, 1954; Donders, 1868; James, 1890). In the present study, however, although the difference between type $\underline{c}$ and type a RTs seemed to be consistent with previous findings, the absolute type a probe RTs, even during the ITI, were about $500 \mathrm{msec}$. long. Posner and Boies also found long type a RTs, but their baseline RT during the 
ITI was at least $100 \mathrm{msec}$. below the baseline in the present study. It seems implausible that a single switching operation to the probe task from the letter-matching task would account for the $350 \mathrm{msec}$. difference in RT, especially since such a long switch at the time of the first letter would probably result in much greater interference than was found. Perhaps factors maintained throughout the experimental sessions, such as the degree of uncertainty about the occurrence of the probe, the priorities, feedback, instructions, and task demands, operated to establish baseline RTs on both the probe task and the lettermatching task. It would seem reasonable for these factors to affect the relative "readiness" with which Ss held the processes and responses for each task.

In conclusion, the data from this study support the hypothesis that encoding of a letter, as well as operations associated with responding, requires attention in the sense of processing capacity. A single-channel switching model accounts for the results more concisely than a model in Which variable amounts of processing capacity may be allocated at the same time. 
References

Averbach, E., E Sperling, G. Short-term storage of information in vision. In C. Cherry (Ed.), Information Theory. London: Butterworths, 1961, 196-211.

Baddeley, A. D. The capacity for generating information by randomization. Quarterly Journal of Experimental Psychology, 1966, 18, 119-129.

Bahrick, H. P., Noble, M., E Fitts, P. M. Extra-task performance as a measure of learning a primary task. Journal of Experimental Psychology, 1954, 48, 298-302. Bertelson, P. The time course for preparation. Quarterly Journal of Experimental Psychology, 1967, 19, 272-279. Binet, A. La concurrence des états psychologiques. Revue Philosophique, $1890, \underline{29}, 138-155$.

Donders, F. C. Over de snelheid van psychische processen. Onder zoekingen gedaan in het Physiologisch Laboratorium der Utrechtsche Hoog,eschool, 1868-1869, Tweede reeks, II, 92-120. Iranslated by W. G. Koster. In W. G. Koster (Ed.), Acta Psychologica 30, Attention and Performance II. Amsterdam: North-Holland Publishing Co., $1969,412-431$.

Lils, J. Attention requirements of movement control. Unpublished doctoral dissertation, University of Oregon, 
1969.

Haber, R. N. Note on how to choose a visual noise mask. Psychological Bulletin, 1970, 74, 373-376. James, W. 'ihe Principles of Psychology. New York: Holt, 1890 .

Jastrow, J., \& Cairnes, W. B. The interference of mental processes--a priliminary survey. American Journal of Psychology, 1891-1892, 4, 219-223.

Kristofferson, A. B. Attention and psychophysical time.

Acta Psychologica, 1967, 27, 93-100.

Moray, N. Where is capacity limited? A survey and a model. Acta Psychologica, 1967, 27, 84-92.

Moray, N. Attention: Selective Processes in Vision and

Hearing. New York: Academic, 1969. Moray, N. Towards a quantitative theory of attention. Acta Psychologica, 1970, 33, 111-117.

Mostofsky, D. I. (Ed.) Attention: Contemporary Theory and Analysis. New York: Appleton-Century-Crofts, 1970. Myers, J. L. Fundamentals of Experimental Design. Boston: Allyn and Bacon, 1966. Neisser, U. Cognitive Psychology. New York: AppletonCentury-Crofts, 1967 .

Paulhan, F. La simultanéité des actes psychiques. Revue Scientifique, $1887,39,684-689$. 
Posner, M. I., E Boies, S. J. Components of attention. Psychological Review, 1971, 78, 391-408. Posner, M. I., Boies, S. J., Eichelman, W. H., E Taylor, R. L. Retention of visual and name codes of single letters. Journal of Experimental Psychology, 1969, $79(1, P t .2)$.

Posner, M. I., E Keele, S. W. Time and space as measures of mental operations. Talk presented at meeting of the American Psychological Association, September, 1970.

Posner, M. I., \& Klein, R. On the functions of consciousness. Paper presented to the IVth International Conference on Attention and Performance, August, 1971. Posner, M. I., E Mitchell, R. F. Chronometric analysis of classification. Psychological Review, 1967, 74, 392409.

Posner, M. I., E Wilkinson, R. T. On the processes of preparation. Paper presented at the meeting of the Psychonomics Society, November, 1969.

Runyon, R. P., E Haber, A. Fundamentals of Behavioral Statistics. Reading, Mass.: Addison-Wesley, 1971. Schvaneveldt, R. W. Effects of complexity in simultaneous reaction time tasks. Journal of Experimental Psychology, 1969, 81, 289-296. 
Smith, M. C. Theories of the psychological refractory period. Psychological Bulletin, 1967, 67, 202-213. Sperlink, G. I'he information available in brief visual presentations. Psychological Monographs, 1960, 74, No. 11. (Whole No. 498 ).

Sperling, G. $\Lambda$ model for visual memory tasks. Invited address, Symposium on Information Processing in Man, University of Southern California, June, 1962. In R. N. Haber (Ld.), Information-Processing Approaches to Visual Perception. New York: Holt, 1.969, 18-31. Swets, J.A., E Kristofferson, A. B. Attention. Annual Review of Psychology, $1970,339-366$.

Woodworth, R. S. Experimental Psychology. New York: Holt, 1938. Woodworth, R. S., E Schlosberg, H. Experimental Psychology. (Revised edition) New York: llolt, 1954. 
Appendix A

Instructions Read at the Beginning of Session 1

The main purpose of this experiment is to determine how quickly and accurately you can classify two stimuli as being the same or different. The stimuli in the experiment will be uppercase and lowercase letters. On each trial the following sequence of events will occur: first a small plus sign will come on in the center of the TV screen as a warning that the first letter will follow in $500 \mathrm{msec}$. $1 \mathrm{msec}$. $=1 / 1000$ of a second, so $500 \mathrm{msec}$. = $1 / 2$ second. The first letter will always appear just to the left of the plus sign and stay on only a short period of time. On some blocks of trials a random pattern of dots called a mask will appear immediately after the first letter and in the same position. It's purpose is to prevent you from seeing an after-image of the first letter. One second after the first letter, the second letter will come on to its right. The first letter will always be uppercase, and the second letter will always be lowercase. The second letter will remain present until you make your response.

As soon after the second letter comes on as you can, you should decide whether the two letters shown have the same name or not. If they are the same (Aa, Tt, etc.), press the "same" key. If they are different (Ab, Tz, etc.), press the "different" key. When you have responded, you will receive feedback about the correctness and speed of your response. If you were correct, the time it took you to make the response will appear in the upper lefthand corner of the 'TV. Try to respond as rapidly as possible, avoiding errors. The time shown will be in msec. If you make an error, the number 1 will appear on the screen instead of your response time.

A few seconds after the feedback goes off, the plus sign will again come on to start the next trial. There will be 8 blocks of trials, each block containing 32 trials. At the end of each block, your average response time and the number of correct trials out of 32 will be displayed. Try not to make more than 3 errors in each block of 32 trials. Before each trial block, you will be 
given information about the conditions of that block-whether the first letter will be followed by a mask or not. You can rest or stretch during that time, and when you want to begin, press this button.

Do you have any questions so far? OK.

Judging whether the two letters are the same or different is your main job in this experiment. We want you to respond as rapidly and as accurately to the letters as you can. However, on some of the trials you will hear a short burst of noise through these headphones, which you can put on just before the first trial actually begins. There are two different kinds of noise tasks. On some blocks of trials you'll hear noises only in your right ear. Whenever you hear the noise, press this button as rapidly as possible. On other blocks of trials, some noises will come to your right ear and some to your left ear, but you should press the noise button only when the noise is in your right ear. These two noise tasks will be identified by either one $E$ or two Es (for one ear or two ears). The purpose of this second task is just to make things a little harder, but try not to let it affect how fast and accurate you are on the letter-matching task. You will not receive feedback about your response time to the noise. However, if you miss a response to the noise, the word "Noise?" will come on after the regular feedback. Then you should press the noise button to continue to the next trial. If you should press the noise button to the wrong noise, the words "Wrong lNoise" will flash on the screen.

Do you have any questions? OK. Remember to concentrate on your speed and accuracy on the letter-matching task but also to respond as fast as you can to the noise.

Instructions Read at the Beginning of Later Sessions.

This session is just like your last session. Remember to be as fast and accurate on the letter-matching task as you can. Try not to make more than 3 errors on each block of trials. Also respond as rapidly as you can to the noise, but try your best not to let it interfere with your performance on the letter-matching task. Any questions? 
Appendix B

B-1. Total Trials Collected Across 14 Ss for Each Probe Position . . . . . . 60

B-2. Percentage of Trials Discarded at Each Probe Position ......... . 61

B-3. Number of Trials Discarded in the No Mask Condition for Errors on the Primary and Probe Tasks . . . . . . 62

B-4. Mean Probe RTs, Standard Deviations, and Standard Errors of the Means. . . . . 63

B-5. Standard Errors of the Difference Between Probe RTs in Conditions NM-E and NM-EE . . . . . . . . . . 64

B-6. Mean RT's on the Letter-Matching Task. . . 65 


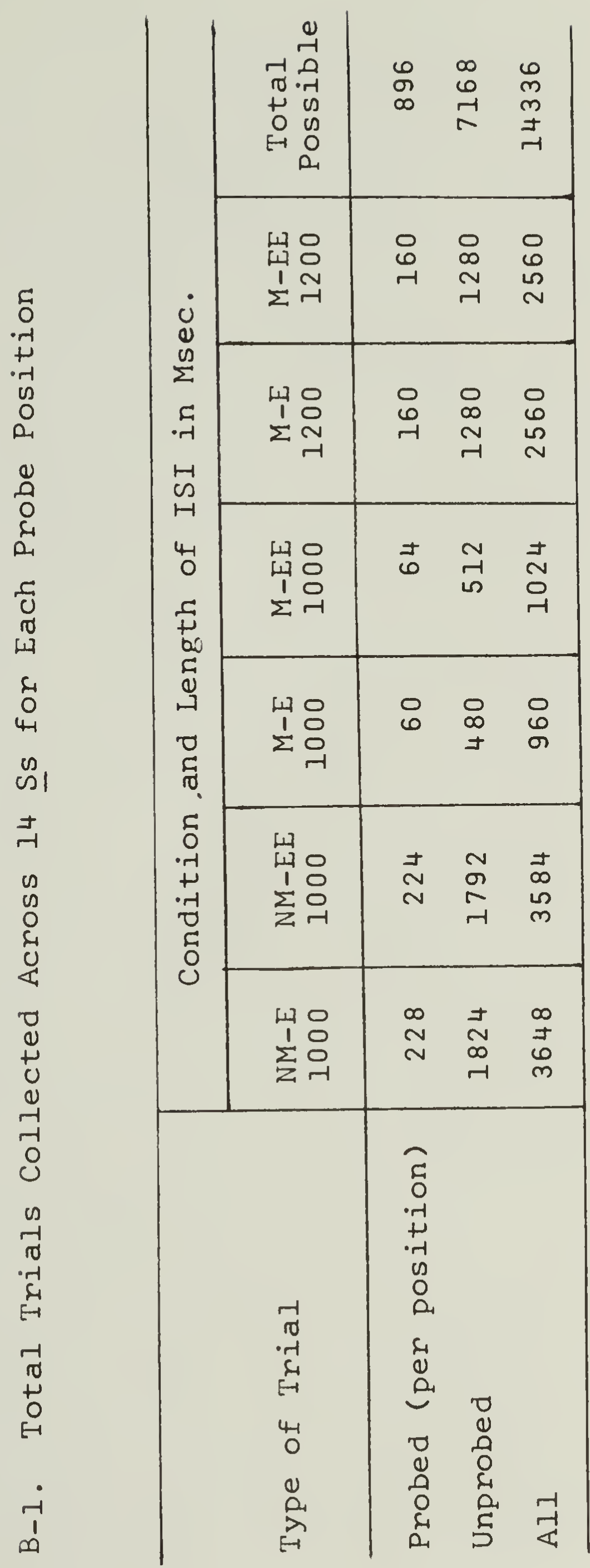




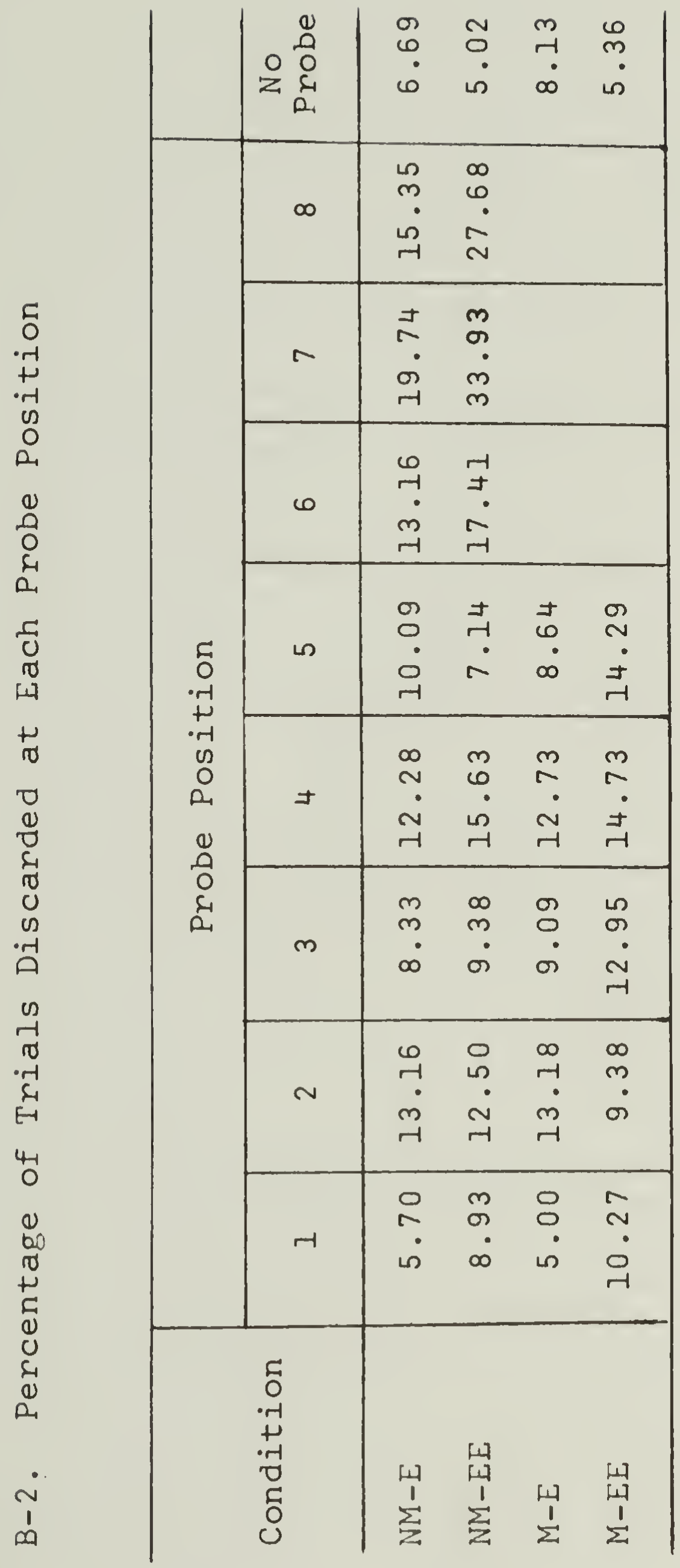




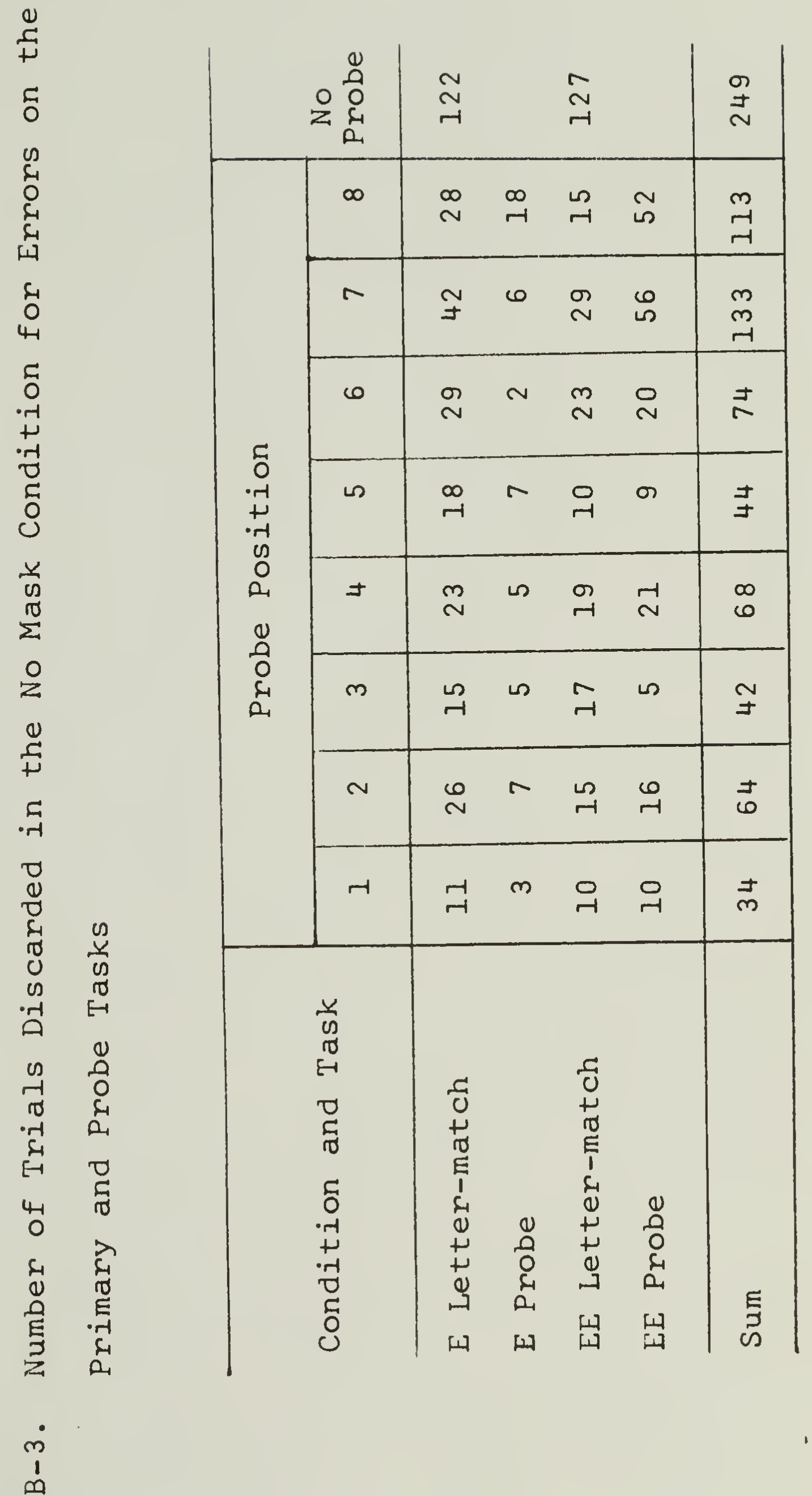




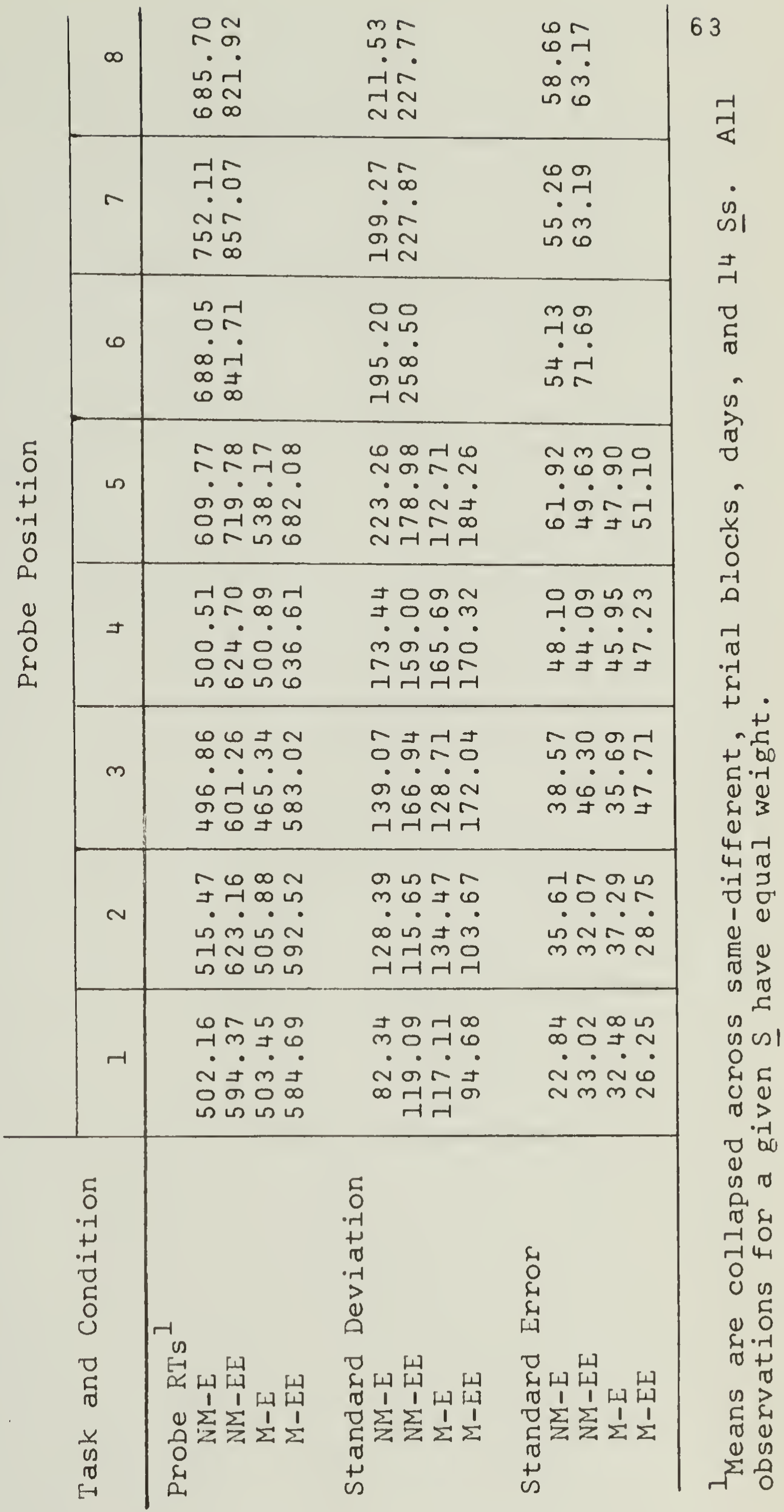




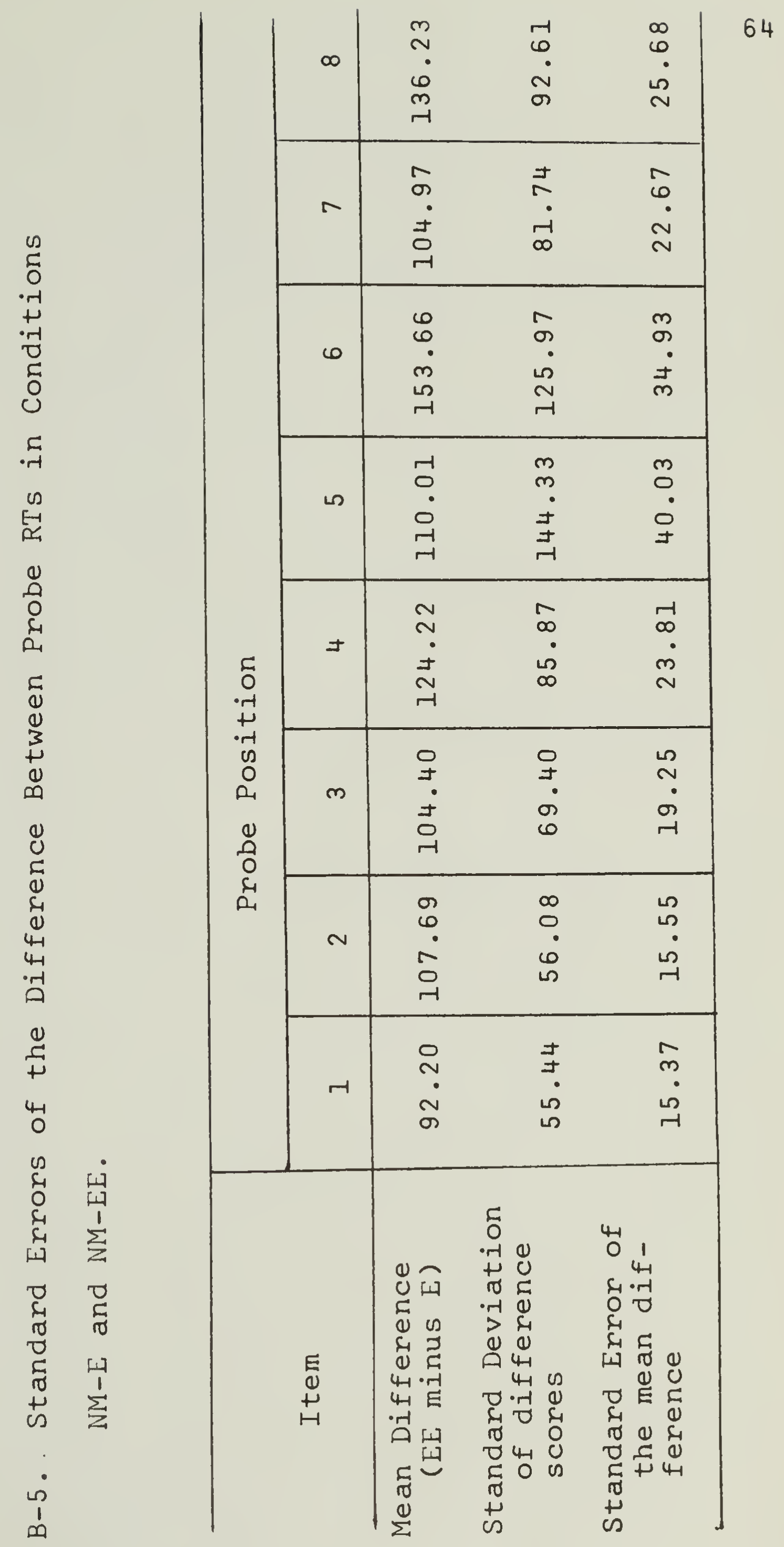




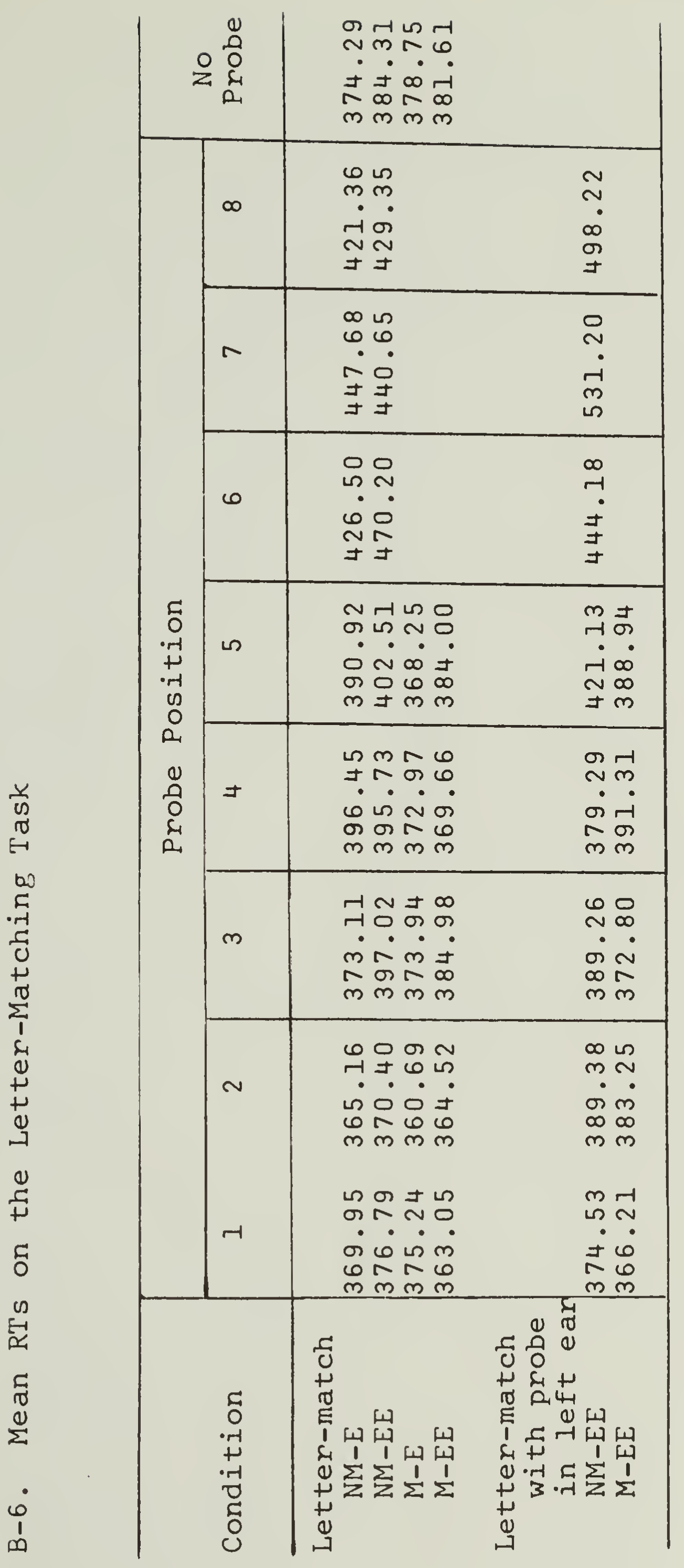


